\title{
Using the Intrusive and Nurturing Models when Advising African American College Students with Learning Disabilities
}

\author{
Wanda M. Hadley
}

Students with disabilities, specifically learning disabilities, continue to be the fastest growing population attending colleges and universities. What makes students with learning disabilities an exclusive student group for the campus community is their educational experience in high school. Due to legislative mandates, high schools are required to identify students with learning disabilities and provide them course accommodations specific to their disabilities. Those mandates do not apply to colleges and universities where students are expected to practice self-determining behavior. In the higher education environment, students with learning disabilities are expected to self-identify and request services. A learning disability can present difficulties for students in their ability to read course materials, present their ideas in class, complete writing assignments, and/or do basic math problems. A student with a learning disability may also have trouble focusing their attention on a particular subject matter for extended periods of time, managing their time efficiently, and interacting appropriately with other students because of poor social skills.

In addition to concerns related to their learning disabilities, African American college students struggle more with personal issues. Studies about this student population indicate that financial and emotional distractions often undermined their academic success. Academic advising can be an important service for retaining African American college students with learning disabilities. Ongoing guidance from a significant person within the university, such as an academic advisor, can be a determining factor in a student's decision to continue at the institution. Academic advisors can be instrumental in helping students reach their academic, personal, and career goals. According to the National Academic Advising Association (NACADA), the primary role of the university advisor is to assist students as they transition to their new academic communities. Advisors should help students to see the importance in the learning process, and help them to set and regularly evaluate their academic goals.

Wanda M. Hadley (whadley@centralstate.edu) is an Associate Editor of The Journal of College Orientation and Transition and an Administrator and Adjunct Faculty member at Central State University (Ohio). 


\section{Intrusive and Nurtured Advising}

As one of the growing at-risk populations on the college campus, African American students with learning disabilities may best be reached through the intrusive and/or nurtured advising models. The less forward, but more traditional, models of prescriptive and developmental advising expect students to seek out their academic advisors. In the prescriptive model the advisor decides what the student needs and gives the student a specific plan to follow. Although developmental advising advocates for planning of goals with the student, the advisor is still responsible for deciding what the student should do. Instead of answering questions, the advisor directs the student to campus resources to encourage independence, problem-solving, and decision-making skills.

Intrusive advising differs from the traditional prescriptive and developmental models by making the initial contact with the student. At-risk students, in particular, can benefit from this approach because they may not always know how to respond to unexpected occurrences. The goal of intrusive advising is to help students feel that the institution cares about them. Students who feel that they belong at the institution tend to be more academically successful than those who do not feel a sense of connectedness. Nurtured advising is a model of advising more common at Historically Black Colleges and Universities (HBCUs), and it goes beyond intrusive advising. HBCUs are known for taking at-risk students and helping them in their development of academic and life skills. In their persistence at the institution, administrators, faculty members, and advisors "adopt" the student and treat them as if they were their own son or daughter.

This approach works on HBCU campuses because the environment is usually smaller. Administrators and faculty members can get to know students more personally. In the nurturing model of advising, advisors replicate the parental/ caregiver role. The assumption is that a parent/caregiver is necessary for the student to keep him/her on track. In my work with African American college students with disabilities, I often find that I have an extended relationship with their families. It does not seem cumbersome or inappropriate, but necessary to keep some students persisting and committed to their education. I have come to realize that some students want, and even expect, intrusive interaction. They come to my office so I can inquire about their attendance in classes, ask about their grades on tests, and/ or question their class schedules each semester. The thinking behind nurtured advising is that when students believe someone at the university cares about them, expects them to do well, and guides their steps, they are more motivated to do their best.

African American students who choose Historically Black Colleges and Universities (HBCUs) are generally thought to have weaker high school and standardized scores than those who choose Predominately White Institutions (PWIs). Intrusive and nurtured advising are effective tools in communicating with, providing support to, and retaining weaker students at the university. For example, in collaboration with faculty members, nurturing advisors can monitor 
students' performance in classes and work with students to develop strategies to be successful in their classes. Intrusive and nurturing advisors can work with the registrar's office to track students' grades toward graduation. Referring students to campus resources such as student academic support services, counseling services, and career services before students are in jeopardy is a responsibility of the intrusive and nurturing advisor.

\section{Conclusion}

Mandatory orientation sessions are an appropriate place to start with intrusive and nurtured advising. Students with learning disabilities are expected to selfidentify in the college setting to the coordinator/director of the office for disability services. While students are meeting with disability services during orientation, they also could be provided with an opportunity to meet with their advisor. This is in line with the intrusive advising principle of proactively reaching out to the student. By showing care and concern but respecting professional boundaries, nurturing advisors extend their role beyond their office setting. By reaching across campus to such places as residence halls, dining facilities, and the student union, advising becomes a teaching process rather than just a means for sharing information. Intrusive and nurturing advisors are key professionals in the success of the institution in graduating competent and competitive students who prepared for additional education and/or the work place. 